Session 2525

\title{
PREPARING DESIGN ENGINEERS FOR THE FUTURE
}

\author{
Laura Bernier, Tony Brune, Elaine Chapman-Moore, \\ Hulas King, and David Wiese \\ Representing Respectively: Sun Microsystems/Sun Microsystems/ \\ General Motors/Unigraphics Solutions/Electronic Data Systems
}

Joined by a panel of PACE Academic Institutional Partner Representatives

\begin{abstract}
The Partnership for the Advancement of CAD/CAM/CAE Education (PACE) is an alliance between General Motors, EDS, Unigraphics Solutions, and Sun Microsystems. Its mission is to integrate math-based, three-dimensional solid modeling-using Unigraphics-into the engineering and design curricula of strategically selected academic institutions worldwide. The PACE Partners are especially committed to working with its academic partners to prepare a new kind of engineer for industry - a design engineer who can engineer and design products, and even perform first-order analysis using parametrics-based software tools. This paper/presentation describes the attributes of the PACE program, and a panel of PACE university partner representatives will share their learnings and insights.
\end{abstract}

\section{What is PACE?}

The Partnership for the Advancement of CAD/CAM/CAE Education (PACE) is a project shared by General Motors (GM), Electronic Data Systems (EDS), Unigraphics Solutions (UGS), and Sun Microsystems to integrate math-based, three-dimensional solid modeling — using Unigraphics—into the design, engineering, and manufacturing curricula of strategically selected academic institutions worldwide. The PACE industrial partners are committed to working with their academic partners to prepare a new kind of engineer for industry - a design engineer - who can engineer and design products, and even perform first-order analysis. PACE also seeks to promote math-based curricula for designers and manufacturing engineers graduating from institutions that are strategic to PACE's mission. The Unigraphics software toolkit brings parametrics to all aspects of styling, product design, testing, and manufacturing approaches. This premier toolkit revolutionizes the way we conduct our engineering and manufacturing businesses. 


\section{History}

PACE was born in 1999 in an effort to encourage the use of three-dimensional solid modeling in universities preparing students for employment in General Motors and its subsidiaries and suppliers. At that time, GM approached three of its primary information technology suppliers with an idea for enhancing the engineering curricula in strategic institutions worldwide. Unigraphics Solutions, the provider of GM's vehicle development software, EDS, the leasing company and service provider of much of GM's design hardware, and Sun Microsystems, a primary hardware manufacturer and provider of computer logistical support to GM, embraced, and even enhanced, this vision-a vision that has already resulted in the contribution of over $\$ 200$ Million worth of hardware, software, and training to PACE institutions.

\section{Guidance and Direction}

Participation by all of the industrial partners is essential to accomplishing the PACE vision. PACE program support begins with several of the top leaders from all four companies, and moves through the ranks as appropriate. The PACE Executive Sponsor Council is comprised of vice-presidential representatives from EDS, GM, UGS, and Sun, joined by GM's Information Officer - Develop Product, and the General Motors University President. This council sets PACE's strategic direction, reviews PACE accomplishments, and assures adherence of the program to its mission.

One of the representatives on this council provides a link to GM's Global Engineering Leadership Council, assuring that PACE expands globally to match the needs of GM's business.

The PACE Steering Committee consists of representatives from all four companies as well as PACE institutions. The Steering Committee makes recommendations on strategy, decisions concerning prioritization of deployment of the project, and determinations on all manner of PACE business. The Steering Committee also forms the basis of the Selection Committee that decides which institutions will become recipients of the various offerings that PACE provides. It is expected that between 25 to 35 institutions around the world will be identified as "PACE Institutions"-i.e., those institutions selected to participate in collaborative phases of PACE to include research, courseware and curriculum development, and industry projects for students.

The PACE Core Team consists of one representative from each of the industrial partner companies and, as a team, they make day-to-day decisions on PACE. They also assure that the details are completed for successful operation.

The Manager of PACE Partnerships provides general coordination of the program, and manages the various partnerships necessary for the success of the program. This 
individual maintains a balance between the partnerships, and manages the administrative systems of PACE.

Ad Hoc Committees and Subcommittees are established as needed.

PACE is guided by written by-laws, approved by all four partners.

\section{PACE Activities}

PACE accomplishes its mission through a variety of activities and phases. Initially it sought to introduce faculty to the capabilities of Unigraphics and three-dimensional solid modeling and its prospective impact on engineering curricula. That phase, entitled the Introductory Offer Phase, provided two Sun workstations, 2 Unigraphics software licenses, and 80 hours of training to selected key institutions in the U.S. Faculty used this phase to evaluate the software for use in their curricula, and determine their interest in other phases of PACE. The PACE Industrial Partners provided more than \$8 Million in educational contributions of hardware, software, and training as a result of this phase.

PACE's Integrated Curriculum Phase provides hardware, software, and training in sufficient critical mass to selected institutions, allowing the faculty to significantly integrate parametrics into their engineering and manufacturing curricula. In most cases, the institutions selected to participate in this phase create PACE Laboratories-providing an opportunity for their students to actively work with this outstanding software. The hardware, software, and training are provided virtually without cost to the institution. This phase provides a framework for these institutions to network with one another and the PACE Industry Partners in parametrics-related efforts. The PACE industrial partners are approximately one-third of the way through the deployment of this phase, but are beginning work on the networks that will bind both the academic and the industrial partners together in efforts to improve design, engineering, and manufacturing approaches worldwide.

Networks for student internships, faculty industrial experiences while on sabbatical, GMspecific and real-life projects for students to complete in their classes, research funds, courseware collaboration, and global collaborative design opportunities between students from global PACE institutions are just some of the networks and activities envisioned.

To date, this phase has provided selected institutions with over $\$ 200$ Million of hardware, software, and training. It has reached institutions in Canada, the U.S., and Mexico. Plans are currently underway to expand this program to institutions in Europe, with the intent of deploying a PACE Institution in Europe before the end of 2001.

\section{Institutional Membership}


To participate in this program, institutions that are considered primary educational partners to General Motors are invited to apply for the respective phase. Applications are reviewed by a 15-person panel consisting of representatives from all four industrial partners and PACE Institutions. Those selected become a part of the "PACE Family," and work to improve their curricula, courseware, research, etc. in parametrics-related areas.

PACE Performance Metrics are currently being defined by a team of PACE Institution representatives, and will form an on-going approach to monitoring the success or shortcomings of the program.

\section{Outcomes and Summary}

The PACE industrial partners join with PACE academic partners to change the way we educate our engineers and designers of the future. PACE pilot institutions report marked improvements in their curricula and academic outcomes as a result of the PACE contributions and focus. The PACE Performance Metrics Committee, consisting of faculty and administrators from the PACE Institutions, is working to identify ways to measure the outcomes from the PACE activities. (These will be reported in the conference presentation.)

\section{Curriculum Vitae}

The authors are all members of the PACE Steering Committee and represent their respective companies on that Committee.

LAURA BERNIER is an Automotive Market Development Specialist for Sun Microsystems; TONY BRUNE is the Client Advisor - Produce Product to General Motors for Sun Microsystems; ELAINE CHAPMANMOORE is the Manager of PACE Partnerships for General Motors; HULAS KING is the Director of Academic Partnerships for Unigraphics Solutions; and DAVE WIESE represents Applied Engineering Solutions - Business Development for EDS. 